\title{
Compartment-Specific Antioxidative Defense in Arabidopsis Against Virulent and Avirulent Pseudomonas syringae
}

\author{
Dominik K. Großkinsky, Barbara E. Koffler, Thomas Roitsch, Romana Maier, and Bernd Zechmann
}

First, second, third, fourth, and fifth authors: University of Graz, Institute of Plant Sciences, Schubertstrasse 51, 8010 Graz, Austria; and fifth author: Graz University of Technology, Institute for Electron Microscopy and Fine Structure Research, Steyrergasse 17, 8010 Graz, Austria.

Accepted for publication 20 March 2012.

\section{ABSTRACT}

Großkinsky, D. K., Koffler, B. E., Roitsch, T., Maier, R., and Zechmann, B. 2012. Compartment-specific antioxidative defense in Arabidopsis against virulent and avirulent Pseudomonas syringae. Phytopathology 102:662-673.

The accumulation of reactive oxygen species (ROS) during biotic stress is either part of a hypersensitive response of the plant or induced directly by the pathogen. Antioxidants such as ascorbate and glutathione counteract the accumulation of ROS and are part of the defense reaction. The aim of the present study was to investigate the compartment-specific importance of ascorbate and glutathione during a virulent and avirulent Pseudomonas syringae infection in Arabidopsis thaliana. Peroxisomes were found to be the hotspot for glutathione accumulation reaching $452 \%$ and $258 \%$ of control levels $24 \mathrm{~h}$ postinoculation during the virulent and avirulent infection, respectively. An accumulation of ascorbate could also be observed in vacuoles during Pseudomonas syringae infection, whereas glutathione remained absent in this cell compartment. Neither glutathione nor ascorbate accumulated in the apoplast during pathogen infection demonstrating an only negligible role of these antioxidants in the apoplast during pathogen infection. Compartment-specific changes followed a recently proposed stress model with an increase of ascorbate and glutathione in most cell compartments at the early stages of infection and a strong drop at the later stage of infection when a strong accumulation of ROS and symptoms occurred in the leaves. This study highlights the importance of certain cell compartments and antioxidants in general for the protection of pathogen-induced ROS accumulation.
Enhanced generation of reactive oxygen species (ROS) is commonly observed during biotic stress situations in plants $(17,39)$. ROS production can be induced by plants in the form of a hypersensitive response (HR) in order to stop the spread of the pathogen (38). This response can lead to the activation of cell death, peroxidase catalyzed cell wall enforcement, synthesis of secondary metabolites such as phytoalexins, and the activation of defense genes. Additionally, the pathogen itself can produce ROS in order to kill the host tissue and toxic components produced by the pathogen can also lead to the accumulation of ROS in the plant $(1,17)$. Enhanced internal ROS production, if not counteracted by antioxidants, can have negative effects on cell structures and plant metabolism since ROS are capable of oxidizing membrane components and proteins, which can lead to the destruction of membranes, proteins, RNA, and DNA, causing mutation and eventually cell death $(12,37,43)$. The antioxidants ascorbate and glutathione are key antagonists of ROS $(12,28,29)$. They protect plants against oxidative stress by detoxifying ROS, either directly or through the ascorbate-glutathione cycle. They also play important roles in redox signaling, the modulation of defense gene expression and they are important for the regulation of enzymatic activities (extensively reviewed in 12,28,29). Therefore, subcellular changes in ascorbate and glutathione contents, especially during biotic stress situations, may provide important insights into compartment-specific defense reactions and reflect the occurrence of compartment-specific oxidative stress. Such information can be used as a subcellular stress marker and can be very helpful in clarifying the importance of the protective roles of ascorbate and

Corresponding author: B. Zechmann; E-mail address: bernd.zechmann@ uni-graz.at

http://dx.doi.org/10.1094/PHYTO-02-12-0022-R

(c) 2012 The American Phytopathological Society glutathione during biotic stress situations in plants on the cellular level.

Changes in compartment-specific glutathione contents and their subcellular roles are well studied during virus infections in plants $(18,50,51)$ but there is still a great lack of knowledge regarding bacterial infections, which differ greatly from virus infections. Bacteria enter the leaf through stomata or wounds and grow intercellularly by using nutrients present inside the plant (32). Virulent bacteria are able to suppress defense reactions of the plants and live off nutrients and water released by the plant into the intercellular spaces $(30,32,38)$. Damages of the host tissue occur rather late in this interaction through the production of toxic compounds and nutrient deprivation by the bacteria $(6,32)$. ROS accumulation is much weaker, correlates with symptom development and is also found in later stages of infection and leads to the death of the infected host tissues in the long term $(1,30,32,38)$. Avirulent bacteria are recognized by the plant, which leads to cell death during $\mathrm{HR}$ and the successful restriction of bacterial proliferation $(38,39)$. ROS accumulation and the development of chlorotic and necrotic lesions occur as part of the HR in the early stages of infection and are controlled by the plant. On the compartment-specific level, chloroplasts are considered to be the main production center for ROS during avirulent infections $(3,14,27$, 36) whereas peroxisomes seem to be involved in stress signaling as they are capable of releasing signaling molecules including ROS (for example $\mathrm{H}_{2} \mathrm{O}_{2}$ and $\mathrm{O}_{2}^{-}$) to the cytosol where they can trigger defense gene expression (9). As antioxidants counteract the accumulation of ROS and are important for the protection of organelles such as the nucleus against oxidative damage (15) their compartment-specific distribution during biotic stress can play important roles in sensing, signaling and activating plant defense. Thus, the aim of this study was to investigate compartmentspecific changes in ascorbate and glutathione content and to link these changes with the accumulation of hydrogen peroxide 
$\left(\mathrm{H}_{2} \mathrm{O}_{2}\right)$ and superoxide anions $\left(\mathrm{O}_{2}^{-}\right)$during virulent and avirulent Pseudomonas syringae infection in Arabidopsis thaliana Col-0 plants.

\section{MATERIALS AND METHODS}

Plant material. Plants were cultivated in growth chambers under defined conditions. After stratification for 4 days at $4^{\circ} \mathrm{C}$ seeds of $A$. thaliana [L.] Heynh. ecotype Columbia (Col-0) were grown on "Naturahum" potting soil (Ostendorf Gärtnereierden $\mathrm{GmbH}$, Vechta, Germany) in growth chambers with 8/16 h day/night photoperiod. Day and night temperatures were 22 and $18^{\circ} \mathrm{C}$, respectively, the relative humidity was $60 \%$, and the plants were kept at $100 \%$ relative soil water content. Light intensity varied between 110 and $140 \mu \mathrm{mol} \mathrm{m} \mathrm{m}^{-2} \mathrm{~s}^{-1}$.

Pathogen inoculation. Infections with the virulent hemibiotrophic bacterium $P$. syringae pv. tomato DC3000 and a corresponding avirulent strain $P$. syringae pv. tomato DC3000 AvrRpm1 were performed according to Großkinsky et al. (16). Bacteria were precultured in culture tubes by transferring colonies from maximum 2-week-old culture plates to $4 \mathrm{ml}$ of Luria-Bertani (LB) medium (7) containing rifampicin at $50 \mathrm{mg} /$ liter (Molekula Limited, Gillingham, Dorset, UK) and tetracycline at $10 \mathrm{mg} / \mathrm{liter}$ (Applichem, Darmstadt, Germany) for the avirulent strain using sterile pipette tips. Precultures were incubated overnight in an incubator at $28^{\circ} \mathrm{C}$ and $180 \mathrm{rpm}$. For main cultures, $50 \mathrm{ml}$ of LB medium containing $50 \mathrm{mg} / \mathrm{liter}$ rifampicin (and $10 \mathrm{mg} / \mathrm{liter}$ tetracycline for the avirulent strain) were inoculated with $1 \mathrm{ml}$ of the preculture in sterile Erlenmeyer flasks. The cultures were incubated at $28^{\circ} \mathrm{C}$ and $180 \mathrm{rpm}$ to an optical density at $600 \mathrm{~nm}$ $\left(\mathrm{OD}_{600 \mathrm{~nm}}\right)$ between 0.4 and 0.8 (exponential growth phase). Cultures were then transferred to $50-\mathrm{ml}$ falcon-tubes and centrifuged with $3,500 \mathrm{rpm}$ at $4^{\circ} \mathrm{C}$ for $10 \mathrm{~min}$. The bacterial pellets were resuspended in a $10 \mathrm{mM} \mathrm{MgCl} 2$ solution and adjusted to $\mathrm{OD}_{600 \mathrm{~nm}}$ of 0.2 which corresponds to $1 \times 10^{8} \mathrm{cfu} / \mathrm{ml}$ (20). For infiltration, suspensions were diluted $1: 100$ with a $10 \mathrm{mM} \mathrm{MgCl} 2$ solution to a final concentration of $1 \times 10^{6} \mathrm{cfu} / \mathrm{ml}$. Prepared suspensions were infiltrated from the abaxial side of $A$. thaliana leaves using a needleless syringe until the whole leaf was fully infiltrated by the solution. Infiltration was carried out once on each half of the leaf (left and right side from the middle vein). Plants were about 8 weeks old at this stage and only one fully developed leaf of the fourth rosette was infiltrated per plant. Control plants were infiltrated with a $10 \mathrm{mM} \mathrm{MgCl}$, solution without bacteria using a needleless syringe into the abaxial side of the leaves as described above. Harvesting of control and $P$. syringae-inoculated samples was performed at the day of inoculation (=control), 12, 24, and $48 \mathrm{~h}$ postinoculation (hpi). For electron microscopical investigations, samples were harvested close to the middle vein where chlorotic symptoms were observed on all leaves at the later stages
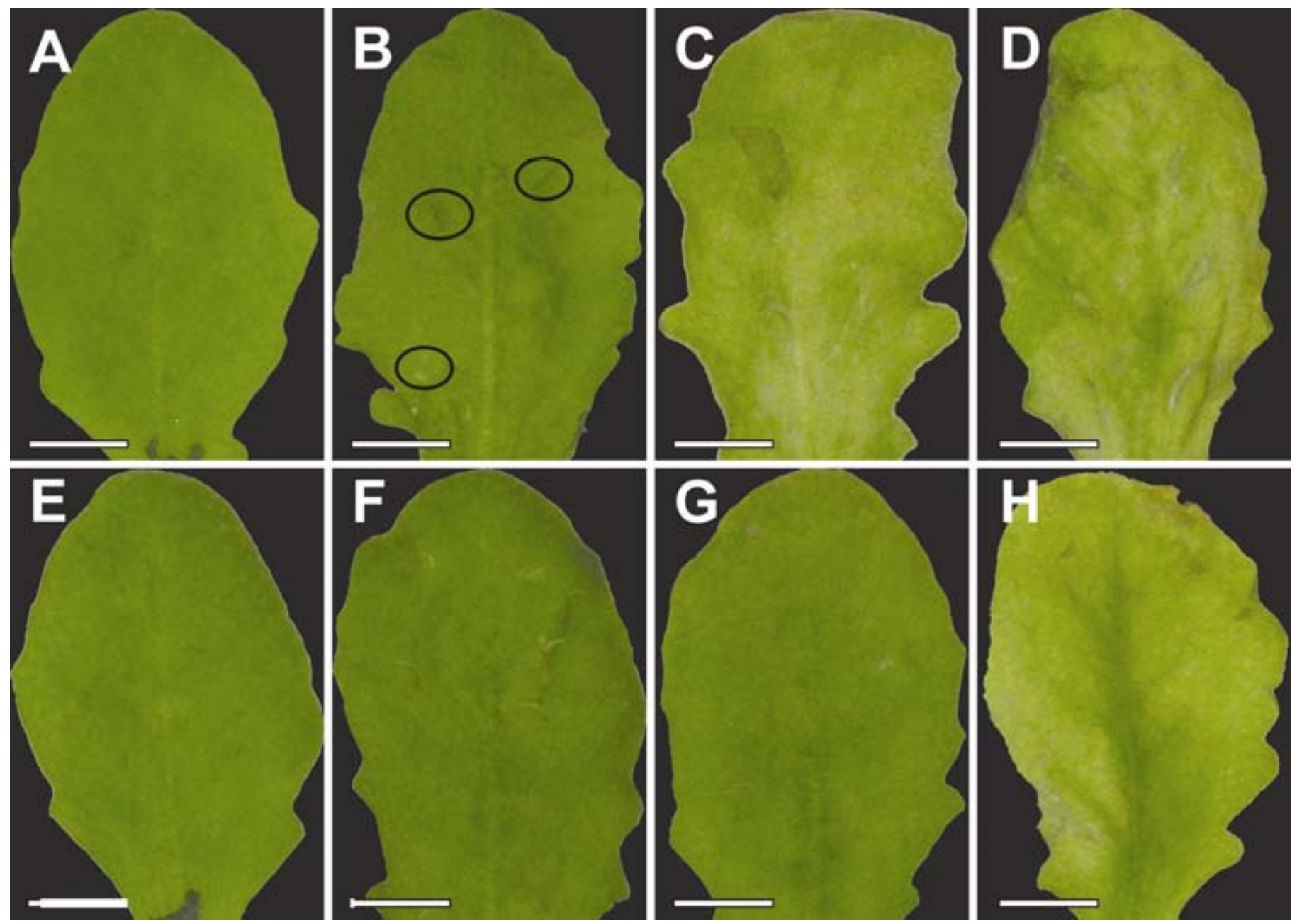

Fig. 1. Symptom development $12 \mathrm{~h}$ postinoculation (hpi) (B and F), $24 \mathrm{hpi}$ (C and G), and 48 hpi (D and H) with Pseudomonas syringae pv. tomato. No symptoms were observed on the controls at the time of inoculation (A) and $48 \mathrm{~h}$ after injection of a $10 \mathrm{mM} \mathrm{MgCl}_{2}$ solution without bacteria (E). First indications of symptoms in the form of local chlorotic and necrotic spots (black circles) could be observed on leaves inoculated with the avirulent strain 12 hpi (B). Clear symptoms (chlorotic and necrotic lesions) could be observed $24 \mathrm{hpi}(\mathbf{C})$ with the avirulent strain which became more severe 48 hpi (D). When leaves were inoculated with the virulent strain no symptoms could be observed 12 hpi (F). First signs of faint chlorosis were observed at 24 hpi, which turned into general chlorosis and local necrotic lesions at $48 \mathrm{hpi}(\mathbf{H})$. Bars $=0.5 \mathrm{~cm}$. 
of infection. Sampling was performed $2 \mathrm{~h}$ after the onset of the light period.

Sample preparation for transmission electron microscopy and immunogold labeling. Preparation of samples for transmission electron microscopy (TEM) and immunogold labeling of glutathione was done with ultrathin sections on nickel grids according to Zechmann et al. $(47,48)$. Small samples of the leaves close to the middle vein (about $1.5 \mathrm{~mm}^{2}$ ) from at least three different plants were cut on a modeling wax plate in a drop of $2.5 \%$ paraformaldehyde and $0.5 \%$ glutardialdehyde in $0.06 \mathrm{M}$ Sørensen phosphate buffer at $\mathrm{pH} 7.2$ (34). Samples were then transferred into glass vials and fixed for $90 \mathrm{~min}$ at room temperature (RT) in the above-mentioned solution. After fixation samples were rinsed in $0.06 \mathrm{M}$ Sørensen phosphate buffer $(\mathrm{pH}$ 7.2) for four times at $15 \mathrm{~min}$ each and dehydrated in increasing concentrations of acetone $(50,70$, and $90 \%$ ) at RT for $20 \mathrm{~min}$ at each step. Subsequently, specimens were gradually infiltrated with increasing concentrations of LR-White resin $(30,60$, and $100 \%$; London Resin Company Ltd., Berkshire, UK) mixed with acetone $(90 \%)$ for a minimum of $3 \mathrm{~h}$ per step. Samples were finally embedded in pure, fresh LR-White resin and polymerized at $50^{\circ} \mathrm{C}$ for $48 \mathrm{~h}$ in small plastic containers under anaerobic conditions. Ultrathin sections $(80 \mathrm{~nm})$ were cut with a Reichert Ultracut S ultramicrotome (Leica Microsystems, Vienna, Austria).

Immunogold labeling of glutathione and ascorbate was done with ultrathin sections on coated nickel grids with the automated

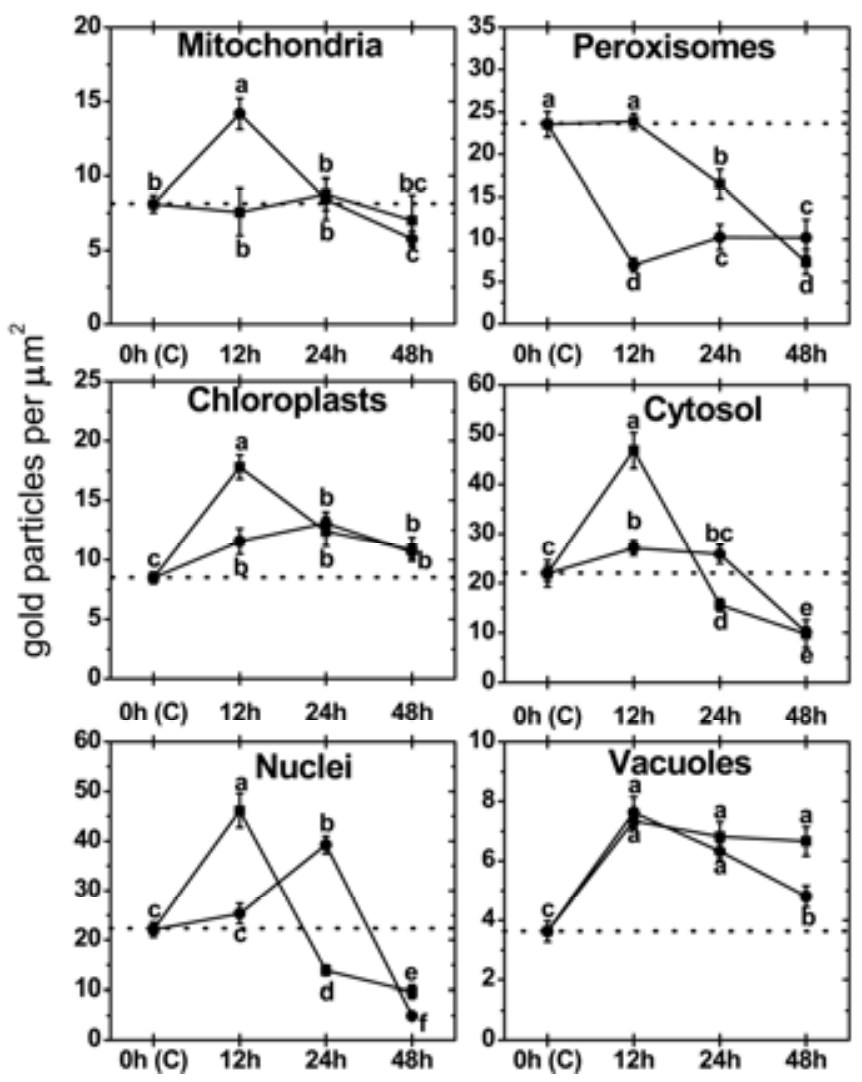

Fig. 2. Compartment specific ascorbate labeling within leaf mesophyll cells of Pseudomonas syringae-inoculated Arabidopsis thaliana Col-0 plants. Measurements were performed 0 (=control, $\mathrm{C}$, represented by the dotted line), 12, 24, and $48 \mathrm{~h}$ postinoculation with the virulent strain Pseudomonas syringae pv. tomato DC3000 (black squares) and avirulent strain Pseudomonas syringae pv. tomato DC3000 AvrRpm1 (black circles). Data show means with standard errors and document the amount of gold particles bound to ascorbate per square micrometer in the respective cell compartment. $n>20$ for peroxisomes and vacuoles and $n>60$ for other cell structures. Different lowercase letters indicate significant differences between the data points. Significant differences were calculated with the Kruskal-Wallis test followed by post-hoc comparison according to Conover at $P<0.05$. immunogold labeling system Leica EM IGL (Leica, Microsystems). The sections were blocked for $20 \mathrm{~min}$ with $2 \%$ bovine serum albumin (BSA, Sigma-Aldrich, St. Louis, MO) in phosphate buffered saline (PBS, pH 7.2) and then treated with the primary antibody against ascorbate (anti-ascorbate rat polyclonal immunoglobulin G [IgG]; Abcam plc, Cambridge, UK) diluted 1:300 in PBS containing 1\% BSA and glutathione (anti-glutathione rabbit polyclonal IgG, Millipore Corp., Billerica, MA) diluted 1:50 in PBS containing 1\% goat serum for $2 \mathrm{~h}$ at RT. After a short rinse in PBS (three times at 5 min each), samples were incubated with a $10 \mathrm{~nm}$ gold-conjugated secondary antibody (goat anti-rabbit IgG for glutathione and goat anti-rat IgG for ascorbate labeled sections, British BioCell International, Cardiff, UK) diluted 1:50 (for sections incubated with the glutathione antibody) and 1:100 (for sections incubated with the ascorbate antibody) in PBS for 90 min at RT. After a short wash in PBS (3 times 5 min) and distilled water (two times $5 \mathrm{~min}$ ), labeled grids were either immediately observed in a Philips CM10 transmission electron microscope or post-stained with uranyl-acetate $(2 \%$ dissolved in aqua bidest) for $15 \mathrm{~s}$.

Micrographs of randomly photographed immunogold labeled sections were digitized and gold particles were counted automatically using the software package Cell D with the particle analysis tool (Olympus, Life and Material Science Europa $\mathrm{GmbH}$, Hamburg, Germany) in different visually identified and manually traced cell structures (mitochondria, plastids, nuclei, peroxisomes, cytosol, and vacuoles). For statistical evaluation at least four different samples were examined. A minimum of 20 (peroxisomes and vacuoles) to 60 (other cell structures) sectioned cell structures of at least 15 different cells were analyzed for gold particle density per sample. The obtained data were statistically evaluated using Statistica (Stat-Soft Europe, Hamburg, Germany) and presented as the number of gold particles per square micrometer. For all statistical analyses the nonparametric Kruskal-Wallis test followed by a post-hoc comparison according to Conover was used. $P<0.05$ was regarded as significant.

Determination of hydrogen peroxide by diaminobenzidine staining. Detection of hydrogen peroxide $\left(\mathrm{H}_{2} \mathrm{O}_{2}\right)$ was performed according to Weigel and Glazebrook (45) by diaminobenzidine (DAB) staining. Therefore, leaves were detached from the plants with a razor blade at the above described time-points and immersed over night at RT in $4 \mathrm{ml}$ of an aqueous solution of $1 \mathrm{mg} / \mathrm{ml}$ DAB (pH 3.8; Roth, Karlsruhe, Germany). To clear leaves, chlorophyll was extracted by incubation in $70 \%$ ethanol at $37^{\circ} \mathrm{C}$. All incubation steps were performed in glass vials. After chlorophyll extraction, the samples were investigated with a stereo microscope (Olympus SZX9) and photographs were taken with a digital camera (Olympus E330).

Determination of superoxide anions by nitroblue tetrazolium staining. Detection of superoxide anions $\left(\mathrm{O}_{2}^{-}\right)$was performed according to Jabs et al. (19) by nitroblue tetrazolium (NBT) staining. Therefore, leaves of different treatments were detached from the plants with a razor blade at the above described time-points and vacuum-infiltrated (two times at $15 \mathrm{~s}$ ) with $10 \mathrm{mM} \mathrm{NaN}_{3}$ in $10 \mathrm{mM}$ potassium phosphate buffer $(\mathrm{pH} \mathrm{7.8)}$ at RT. Next, leaves were immersed at RT for $20 \mathrm{~min}$ in $10 \mathrm{mM}$ potassium phosphate buffer containing 0.1\% NBT (AppliChem, Darmstadt, Germany). To clear leaves, chlorophyll was extracted by incubation in $70 \%$ ethanol at $37^{\circ} \mathrm{C}$. All incubation steps were performed in glass vials. After chlorophyll extraction, the samples were investigated with a stereo microscope (Olympus SZX9) and photographs were taken with a digital camera (Olympus E330).

\section{RESULTS}

Symptom development. Symptom development was evaluated over a time period of $48 \mathrm{hpi}$ on plants inoculated with the avirulent and the virulent strain of $P$. syringae pv. tomato. Control 
plants which were injected with a $10 \mathrm{mM} \mathrm{MgCl}$ solution without bacteria did not develop symptoms throughout the time of investigation (Fig. 1A and E). Plants inoculated with the avirulent strain showed first symptoms in the form of local chlorotic and necrotic spots at 12 hpi (Fig. 1B). These symptoms became more prominent 24 hpi when yellowing occurred on the whole leaf and necrotic spots increased in size (Fig. 1C). Symptom development became even more severe 48 hpi when yellowing of the leaves progressed and an increase in number and size of necrotic spots could be observed (Fig. 1D). Leaves inoculated with the virulent strain showed no symptoms at 12 hpi (Fig. 1F). First signs of faint chlorosis could be observed at 24 hpi (Fig. 1G) which correlated somewhat with the chlorosis observed on plants inoculated with the avirulent strain at $12 \mathrm{hpi}$. A general chlorosis and local necrotic lesions were observed on plants inoculated with the virulent strain at $48 \mathrm{hpi}$ (Fig. 1H). In general, the development of chlorosis and necrosis occurred earlier and was more severe on leaves inoculated with the avirulent strain when compared with
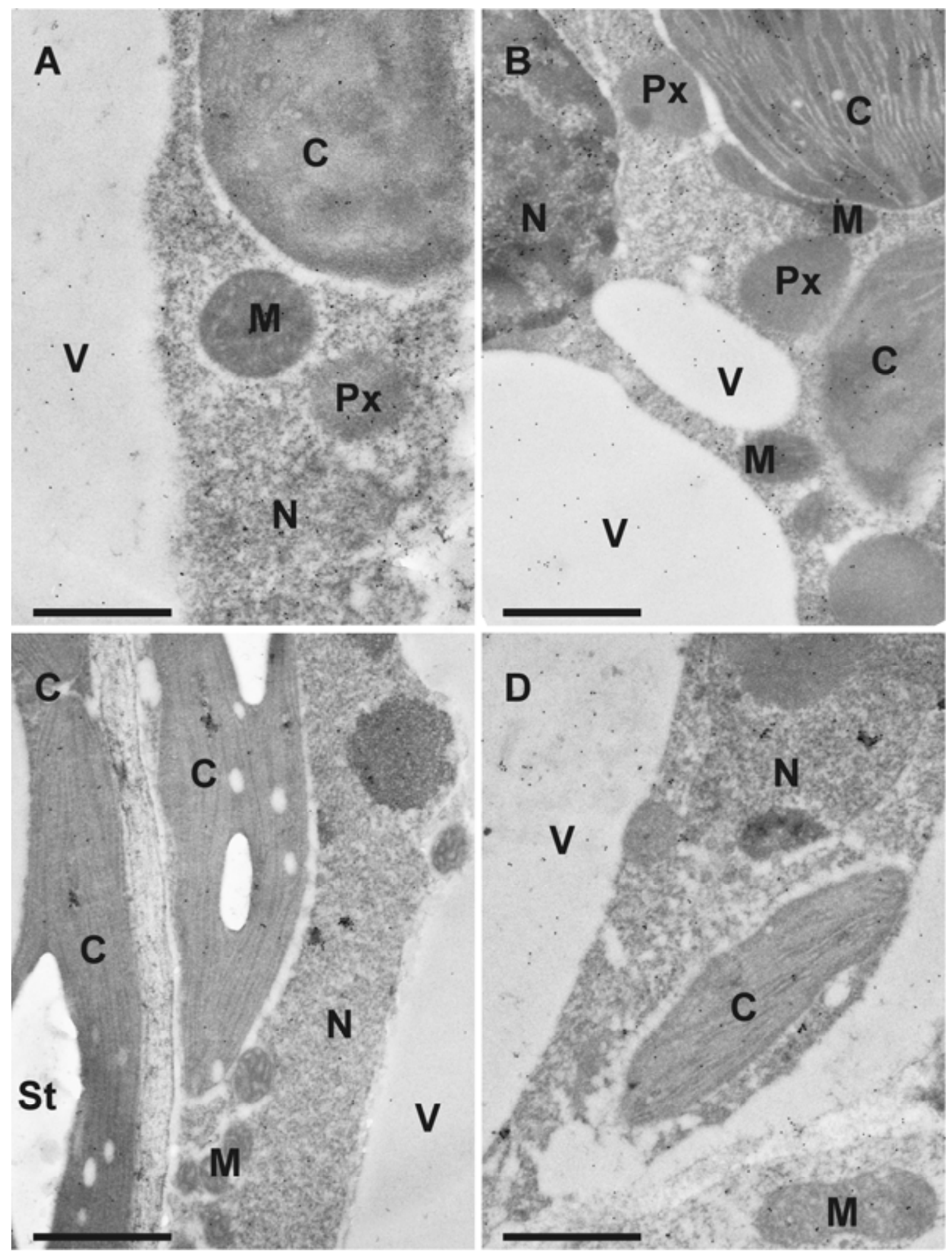

Fig. 3. Transmission electron micrographs showing the subcellular distribution of ascorbate in Arabidopsis thaliana Col-0 leaf cells inoculated with the virulent strain Pseudomonas syringae pv. tomato DC3000 at the day of inoculation $(\mathbf{A}), 12 \mathrm{~h}$ postinoculation (hpi) $(\mathbf{B}), 24 \mathrm{hpi}(\mathbf{C})$, and $48 \mathrm{hpi}(\mathbf{D})$. C $=$ chloroplasts with or without starch ( $\mathrm{St}$ ), $\mathrm{M}=$ mitochondria, $\mathrm{N}=$ nuclei, $\mathrm{Px}=$ peroxisomes, and $\mathrm{V}=$ vacuoles. Bars $=1 \mu \mathrm{m}$. 
symptom development on leaves inoculated with the virulent strain.

Ascorbate. Subcellular changes of ascorbate labeling were investigated by TEM at 12,24 , and 48 hpi of A thaliana Col-0 plants with a virulent and avirulent strain of $P$. syringae. Control plants, which were mock-inoculated by injection of a $10 \mathrm{mM}$ $\mathrm{MgCl}_{2}$ solution without bacteria, showed similar (not significantly different) subcellular ascorbate contents 12,24 , and $48 \mathrm{~h}$ after the injection of the solution (data not shown). Therefore, a mean of the determined subcellular ascorbate contents of these time-points was calculated, defined as control and used for calculating significant differences between mock and $P$. syringae-inoculated plants at 12, 24, and 48 hpi. Subcellular ascorbate contents significantly increased (75\%) $12 \mathrm{hpi}$ in mitochondria during the avirulent infection but remained statistically unchanged in the compatible interaction (Figs. 2 to 4). Unchanged levels of ascorbate were found in mitochondria during the virulent and avirulent infection 24 hpi. Whereas mitochondria showed a significant
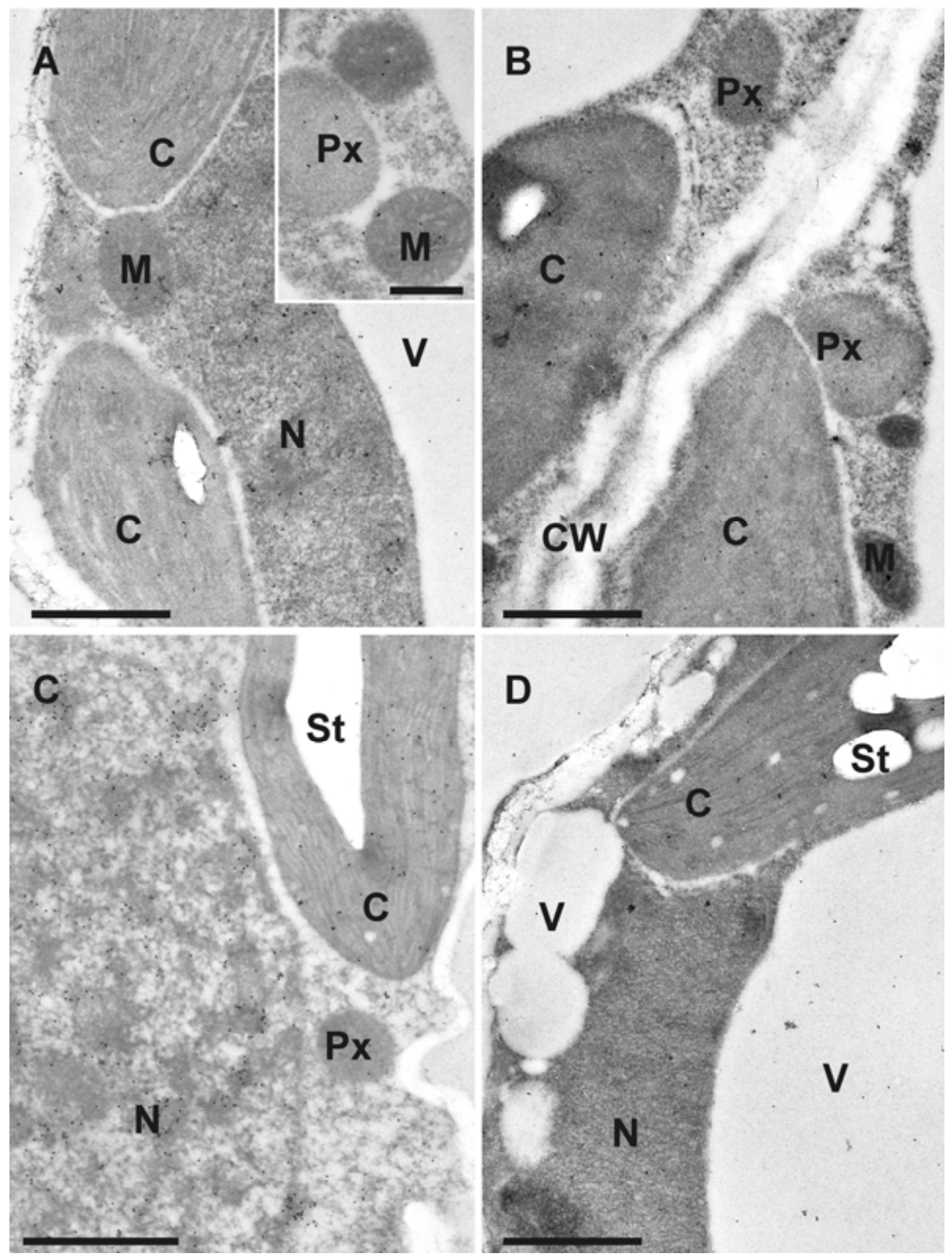

Fig. 4. Transmission electron micrographs showing the subcellular distribution of ascorbate in Arabidopsis thaliana Col-0 leaf cells inoculated with the avirulent strain Pseudomonas syringae pv. tomato DC3000 AvrRpm1 at the day of inoculation $(\mathbf{A}), 12 \mathrm{~h}$ postinoculation $(\mathrm{hpi})(\mathbf{B}), 24 \mathrm{hpi}(\mathbf{C})$, and $48 \mathrm{hpi}(\mathbf{D})$. C = chloroplasts with or without starch $(\mathrm{St}), \mathrm{CW}=$ cell walls, $\mathrm{M}=$ mitochondria, $\mathrm{N}=$ nuclei, $\mathrm{Px}=$ peroxisomes, and $\mathrm{V}=$ vacuoles. Bars $=1$ and $0.5 \mu \mathrm{m}$ in inset. 
decrease of ascorbate contents of about $29 \%$ during the avirulent infection, unchanged levels were detected during the virulent infection 48 hpi. A significant increase of ascorbate contents was observed in chloroplasts during the avirulent (36\% at $12 \mathrm{hpi}, 54 \%$ at $24 \mathrm{hpi}$, and $25 \%$ at $48 \mathrm{hpi})$ and virulent $(110 \%$ at $12 \mathrm{hpi}, 46 \%$ at $24 \mathrm{hpi}$, and $28 \%$ at $48 \mathrm{hpi}$ ) infection over the whole time period (Fig. 2). Ascorbate contents in nuclei were significantly increased (109\%) 12 hpi during the virulent infection but remained statistically unchanged in the incompatible interaction. A decrease (37\%) of ascorbate specific labeling was observed 24 hpi in the virulent infection whereas an increase of about $77 \%$ was found at this time-point in the avirulent infection. Decreased ascorbate contents of 56 and $78 \%$ in comparison to the control were observed in nuclei 48 hpi during the virulent and avirulent infection (Fig. 2). In peroxisomes unchanged levels of ascorbate were detected 12 hpi during the virulent infection, whereas significant decreased levels of ascorbate specific labeling (70\%) were detected during the avirulent infection at this time-point. A decrease of ascorbate labeling in peroxisomes was observed at $24 \mathrm{hpi}$ and $48 \mathrm{hpi}$ in the virulent (30 and 69\%) and the avirulent infection (56 and $57 \%$ ). Ascorbate accumulated in the cytosol at $12 \mathrm{hpi}$ during the virulent (113\%) and the avirulent (23\%) infection (Fig. 2). Whereas a significant decrease in ascorbate specific labeling was observed 24 hpi in the virulent infection (29\%), similar levels as observed in the control occurred in the cytosol during the avirulent infection. A decrease of ascorbate labeling was found during the virulent $(56 \%)$ and the avirulent $(54 \%)$ infection 48 hpi. An accumulation of ascorbate specific labeling was detected in vacuoles in the virulent $(103 \%$ at $12 \mathrm{hpi}, 88 \%$ at $24 \mathrm{hpi}$, and $84 \%$ at $48 \mathrm{hpi}$ ) and the avirulent ( $111 \%$ at $12 \mathrm{hpi}, 74 \%$ at $24 \mathrm{hpi}$, and $32 \%$ at 48 hpi) infection (Figs. 2 to 4). Ascorbate could not be detected in the apoplast of control plants and plants infected with the virulent and avirulent $P$. syringae strain (Figs. 3 and 4 ).

Glutathione. Subcellular changes of glutathione labeling were investigated by TEM at 12,24 , and 48 hpi of A. thaliana Col-0 plants with a virulent and avirulent strain of $P$. syringae. Control plants, which were mock-inoculated by injection of a $10 \mathrm{mM}$ $\mathrm{MgCl}_{2}$ solution without bacteria, showed similar (not significantly different) subcellular glutathione contents at 12,24 , and $48 \mathrm{~h}$ after the injection of the solution (data not shown). Therefore, a mean of the determined subcellular glutathione contents of these timepoints was calculated, defined as control and used for calculating significant differences between mock and $P$. syringae inoculated plants at 12, 24, and 48 hpi. Subcellular glutathione contents were heavily affected by $P$. syringae infection. In mitochondria, an initial significant increase of glutathione of 44 and $29 \%$ was detected 12 hpi during the virulent and the avirulent infection (Figs. 5 to 7). Glutathione contents remained statistically unchanged 24 hpi and significantly decreased about $29 \%$ in the virulent infection $48 \mathrm{hpi}$. In chloroplasts, a significant increase of glutathione labeling was detected in the virulent (73\%) and avirulent $(25 \%)$ infection 12 hpi. Whereas glutathione contents were even more strongly increased in the virulent infection 24 hpi $(133 \%)$, control values were detected in the chloroplasts in the avirulent infection at this stage (Fig. 5). Glutathione contents were significantly decreased in chloroplasts 48 hpi during the virulent $(48 \%)$ and avirulent $(40 \%)$ infection. Glutathione contents in nuclei were statistically elevated to about $53 \%$ in the avirulent infection 12 hpi but remained at control values in the virulent interaction. A significant increase in nuclei of about 158 and $70 \%$ was detected 24 hpi during the virulent and avirulent infection, respectively (Fig. 5). At 48 hpi, glutathione contents were significantly increased to 70 and $38 \%$ in nuclei during the compatible and incompatible interaction. In peroxisomes glutathione contents remained similar to control values in the virulent infection but were significantly increased (139\%) during the avirulent infection 12 hpi (Fig. 5). A strong increase of glutathione-specific labeling during the virulent and the avirulent infection (452 and 258\%) was found 24 hpi. At 48 hpi, a strong decrease of glutathione contents of about 48 and $39 \%$ was found during the compatible and incompatible interaction. Glutathione contents in the cytosol were significantly increased $12 \mathrm{hpi}$ during the avirulent infection (143\%) but showed unchanged levels during the virulent infection (Fig. 5). A strong increase of glutathione contents of 307 and $160 \%$ was found 24 hpi in the virulent and avirulent infection, respectively. In the virulent infection glutathione labeling remained unchanged at 48 hpi but was significantly decreased during the avirulent infection (41\%) (Figs. 5 to 7). Glutathione could not be detected in the apoplast and vacuoles of control plants and plants infected with the virulent and avirulent $P$. syringae strain (Figs. 6 and 7).

Determination of hydrogen peroxide by DAB staining. DAB staining revealed the first signs of $\mathrm{H}_{2} \mathrm{O}_{2}$ accumulation in the form of small light brown stained areas on the leaves of plants inoculated with the avirulent strain of $P$. syringae 12 hpi (Fig. 8B). At this time-point no staining was observed on plants inoculated with the virulent strain (Fig. $8 \mathrm{~F}$ ). $\mathrm{H}_{2} \mathrm{O}_{2}$ accumulation, visualized in the form of larger light brown stained areas on the leaves, became more prominent at $24 \mathrm{hpi}$ and reached its maximum at 48 hpi on leaves of plants inoculated with the avirulent strain when most of the leaf was heavily stained by DAB (Fig. 8C and $\mathrm{D}$, respectively). The first signs of $\mathrm{H}_{2} \mathrm{O}_{2}$ accumulation in the form of brown spots became visible on plants inoculated with the virulent strain at $24 \mathrm{hpi}$ and reached its maximum at $48 \mathrm{hpi}$ when

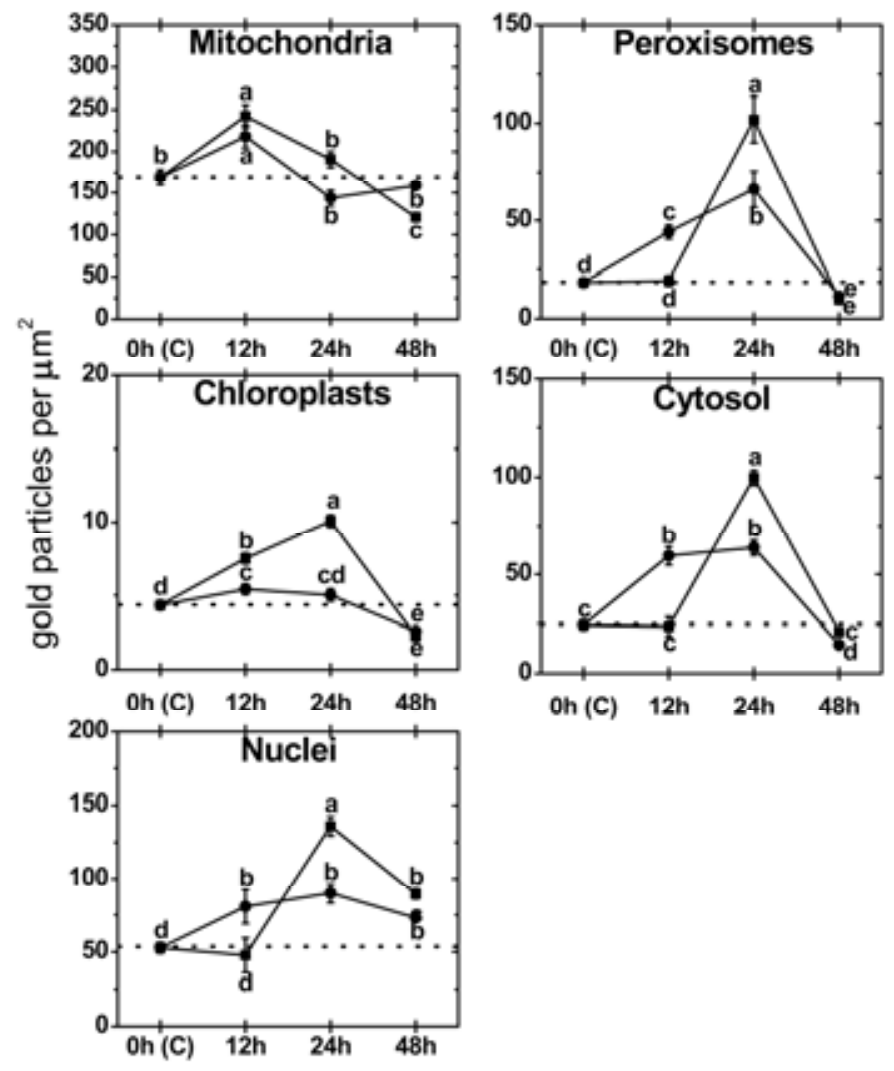

Fig. 5. Compartment specific glutathione labeling within leaf mesophyll cells of Pseudomonas syringae-inoculated Arabidopsis thaliana Col-0 plants. Measurements were performed 0 ( $=$ control, $\mathrm{C}$, represented by the dotted line), 12, 24, and $48 \mathrm{~h}$ postinoculation with the virulent strain Pseudomonas syringae pv. tomato DC3000 (black squares) and avirulent strain Pseudomonas syringae pv. tomato DC3000 AvrRpm1 (black circles). Data show means with standard errors and document the amount of gold particles bound to glutathione per square micrometer in the respective cell compartment. $n>$ 20 for peroxisomes and vacuoles and $n>60$ for other cell structures. Different lowercase letters indicate significant differences between the data points. Significant differences were calculated with the Kruskal-Wallis test followed by post-hoc comparison according to Conover at $P<0.05$. 
larger light brown areas appeared on the leaves (Fig. 8G and $\mathrm{H}$ ). Staining by far did not reach the same intensity as found in leaves inoculated with the avirulent strain at $48 \mathrm{hpi}$. No or only very little DAB staining could be observed on control plants at $0 \mathrm{~h}$ and 48 hpi (Fig. 8A and E, respectively).

Determination of superoxide anions by NBT staining. A strong accumulation of $\mathrm{O}_{2}{ }^{-}$could be observed in the form of blue stained areas all over the leaves of plants inoculated with the avirulent strain of $P$. syringae at 12 hpi (Fig. 9B). NBT staining remained similar during the avirulent infection $24 \mathrm{hpi}$ and $48 \mathrm{hpi}$ (Fig. 9B to D). The accumulation of $\mathrm{O}_{2}^{-}$was much weaker in plants inoculated with the virulent strain where first signs of $\mathrm{O}_{2}^{-}$ could be observed 24 hpi. Only small blue stained areas indicating the presence of $\mathrm{O}_{2}^{-}$could be observed at this time (Fig. 9G). A strong accumulation of $\mathrm{O}_{2}^{-}$could be observed 48 hpi in leaves of plants inoculated with the virulent strain of $P$. syringae
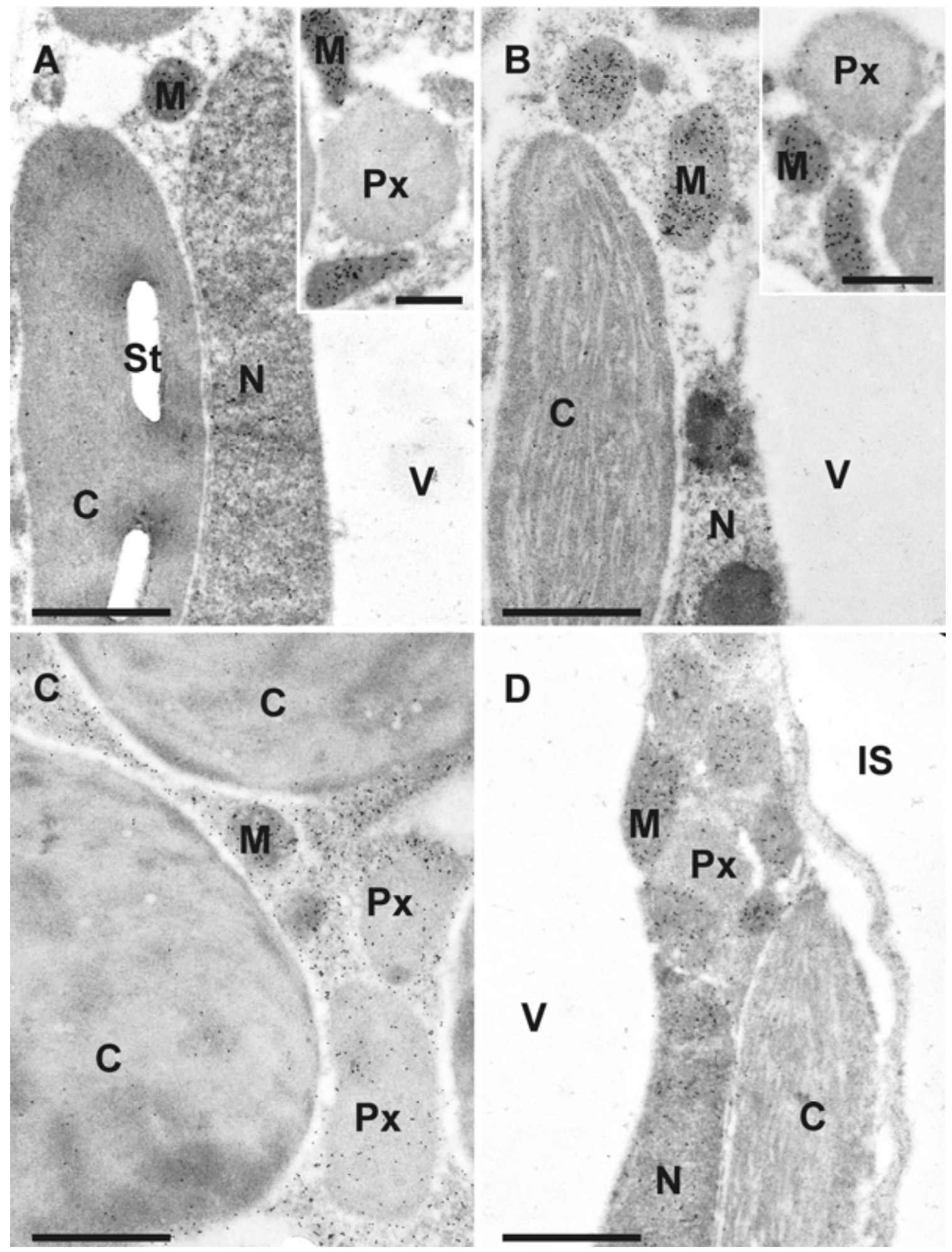

Fig. 6. Transmission electron micrographs showing the subcellular distribution of glutathione in Arabidopsis thaliana Col-0 leaf cells inoculated with the virulent strain Pseudomonas syringae pv. tomato DC3000 at the day of inoculation $(\mathbf{A}), 12 \mathrm{~h}$ postinoculation (hpi) $(\mathbf{B}), 24 \mathrm{~h}(\mathbf{C})$, and $48 \mathrm{~h}(\mathbf{D})$ after inoculation. C $=$ chloroplasts with or without starch $(\mathrm{St}), \mathrm{IS}=$ intercellular space, $\mathrm{M}=$ mitochondria, $\mathrm{N}=$ nuclei, $\mathrm{Px}=$ peroxisomes, and $\mathrm{V}=\mathrm{vacuoles}$. Bars $=1$ and $0.5 \mu \mathrm{m}$ in insets. 
(Fig. 9H). No or only very little NBT staining could be observed on control plants at $0 \mathrm{~h}$ and $48 \mathrm{hpi}$ (Fig. 9A and E).

\section{DISCUSSION}

The results revealed clear differences in the accumulation of ROS and the counteracting antioxidants ascorbate and glutathione between the virulent and avirulent $P$. syringae infection in $A$. thaliana. Plants infected with the avirulent strain showed a much earlier and stronger accumulation of $\mathrm{H}_{2} \mathrm{O}_{2}$ and $\mathrm{O}_{2}^{-}$(starting $12 \mathrm{hpi}$ with heaviest accumulation $48 \mathrm{hpi}$ ) than the virulent strain where first signs could only be observed at 24 hpi (Figs. 8 and 9). Avirulent infections are characterized by the induction of HR, which leads to the induction of cell death mediated by the accumulation of ROS early in the infection period as observed in this study in order to constrain the spread of the pathogen (38).
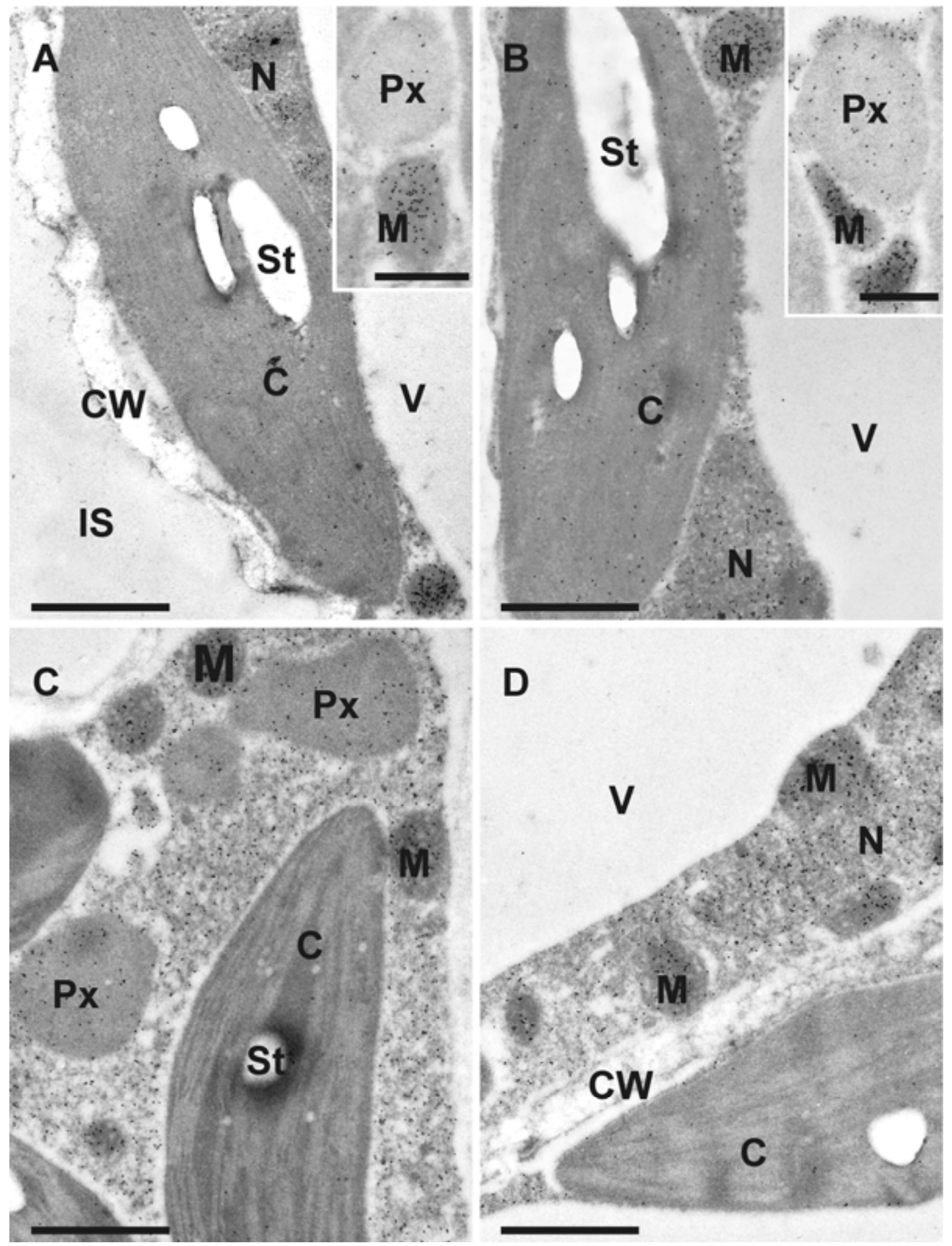

Fig. 7. Transmission electron micrographs showing the subcellular distribution of glutathione in Arabidopsis thaliana Col-0 leaf cells inoculated with the avirulent strain Pseudomonas syringae pv. tomato DC3000 AvrRpm1 at the day of inoculation $(\mathbf{A}), 12 \mathrm{~h}$ postinoculation $(\mathrm{hpi})(\mathbf{B}), 24 \mathrm{hpi}(\mathbf{C})$, and $48 \mathrm{hpi}(\mathbf{D})$. C $=$ chloroplasts with or without starch $(\mathrm{St}), \mathrm{CW}=$ cell walls, $\mathrm{IS}=$ intercellular space, $\mathrm{M}=$ mitochondria, $\mathrm{N}=$ nuclei, $\mathrm{Px}=$ peroxisomes, and $\mathrm{V}=$ vacuoles. $\mathrm{Bars}=1$ and $0.5 \mu \mathrm{m}$ in insets. 
The accumulation of ROS starting at 12 hpi during the avirulent infection was accompanied by a strong accumulation of ascorbate and glutathione in most cell compartments during the early stages of infection (12 and $24 \mathrm{hpi}$ ) and a sharp drop at $48 \mathrm{hpi}$ when ROS reached their maximum levels (Figs. 8 and 9). These results clearly demonstrate that ascorbate and glutathione counteracted the accumulation of ROS during the early stages of the HR but were not able to keep the accumulation of ROS under control in the long term. ROS accumulation was eventually leading to the development of chlorotic and necrotic lesions, which are typical signs observed during HR (Fig. 1). A different effect was found during the virulent infection. Whereas ascorbate contents showed the strongest increase 12 hpi (Fig. 2), glutathione contents accumulated later at 24 hpi (Fig. 5) when first signs of ROS accumulation could be observed by light microscopy during the virulent infection (Figs. 8 and 9). Compatible interactions are characterized by the induction of ROS in the later stages of infection either by the bacteria itself or by toxic components released by the bacteria inside the infected tissue $(6,17,30,32,38)$. Thus, we can conclude that the accumulation of glutathione contents correlated well with the occurrence of oxidative stress (12 and 24 hpi in the avirulent and virulent infection, respectively) highlighting the importance of glutathione in the protection of $P$. syringae-infected A. thaliana plants against ROS (1). As a strong accumulation of ascorbate was additionally found prior to the occurrence of ROS (12 hpi) in the virulent infection (Fig. 2 ), it can also be concluded that ascorbate might take over additional roles in the defense response (e.g., signaling of basal resistance) besides solely the detoxification of ROS. Even though glutathione accumulated later (24 hpi) during the virulent infection (Fig. 5), it can be summarized that in general the virulent and avirulent $P$. syringae infection are both characterized by an accumulation of ascorbate and glutathione in most cell compartments in the early stages of infection and by a strong drop at 48 hpi when ROS accumulation is strongest and symptom development in the form of chlorotic and necrotic lesions appear (Fig. 1). These results fit well in a recently proposed general stress model for plant material involving antioxidants (22). In the proposed model, plants activate the antioxidant system during the alarming and resistance phase, which correlates well with the accumulation of glutathione and ascorbate during the early stages of infection (12 and $24 \mathrm{hpi}$ ) in this study. Antioxidants play important roles in these stages for stress signaling, protection and repair of plant compounds and metabolic pathways. The exhaustion phase is defined by the increasing failure of protection and repair mechanisms correlating with decreased concentrations of antioxidants and accumulation of ROS, which eventually lead to cell death (22), as could be observed during the later stages of $P$. syringae infection in A. thaliana in this study (Fig. 1).
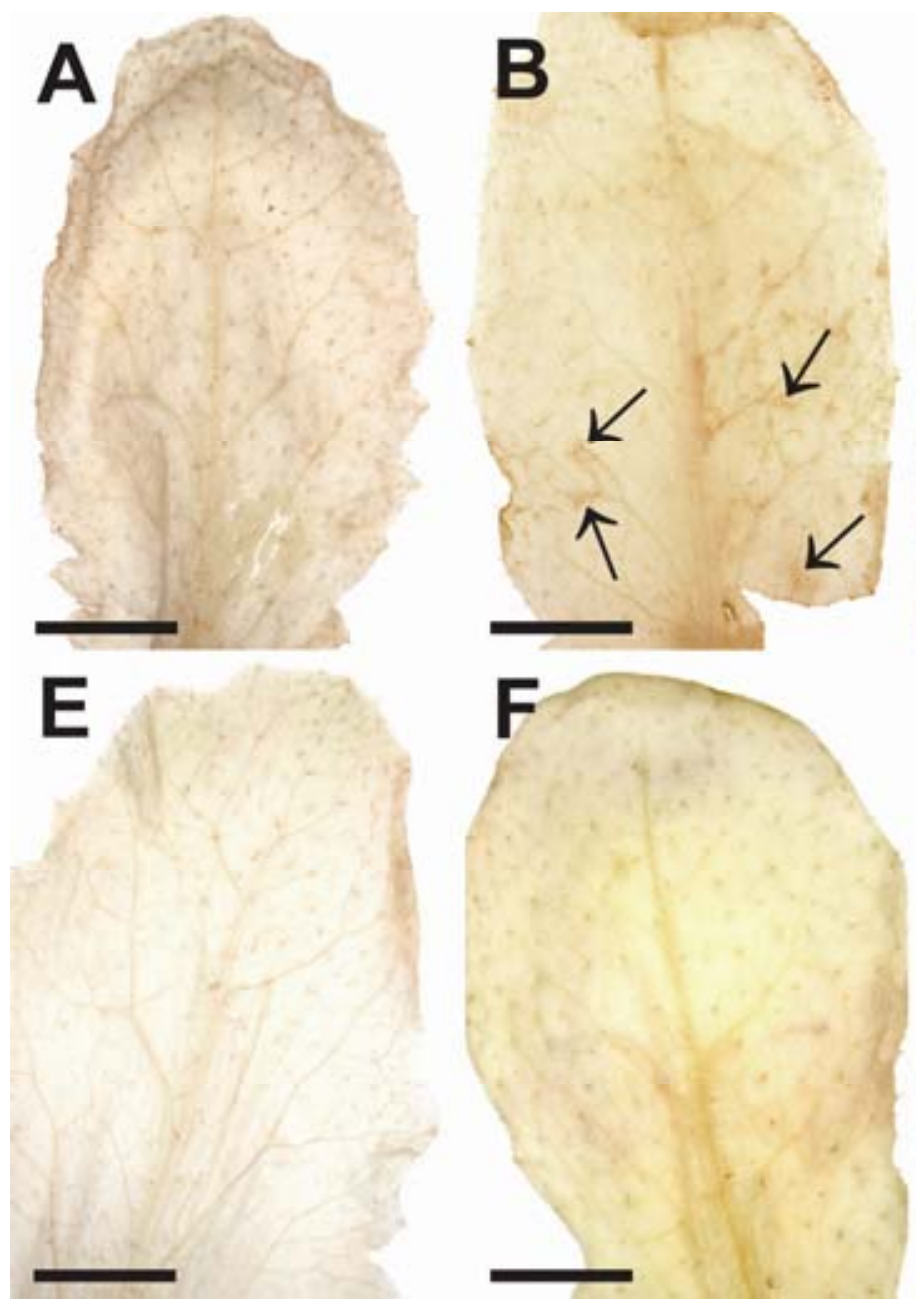
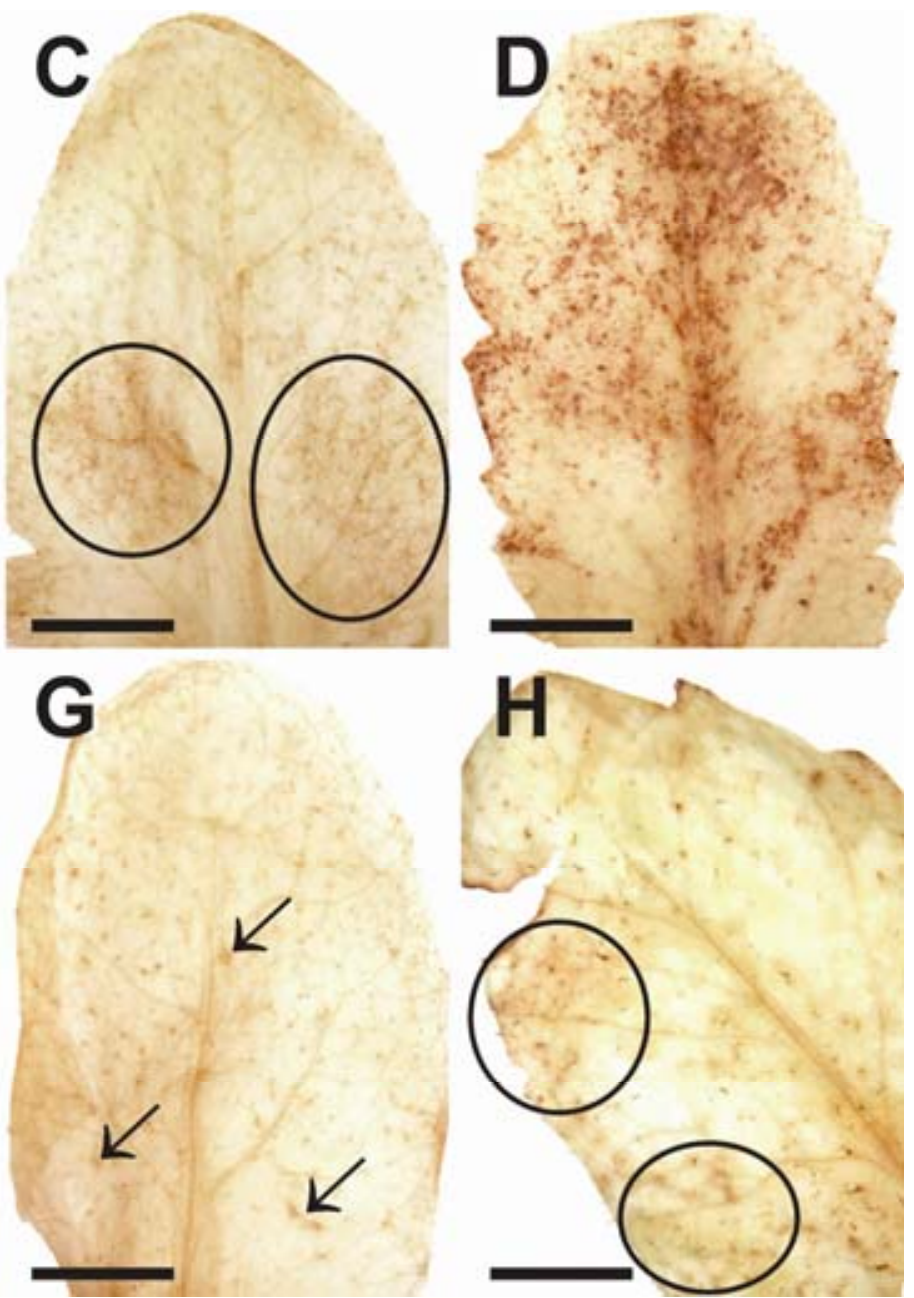

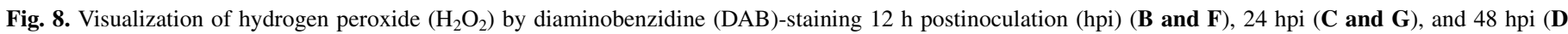

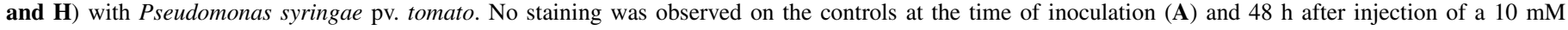

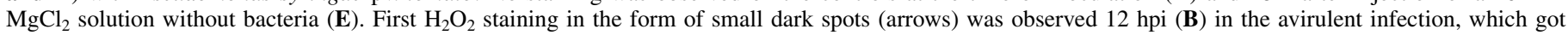

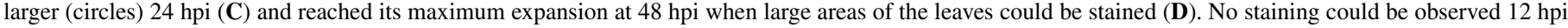

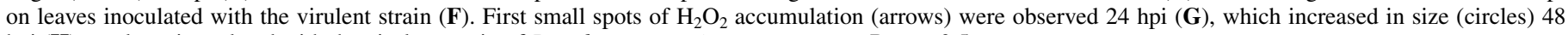
hpi $(\mathbf{H})$ on plants inoculated with the virulent strain of Pseudomonas syringae pv. tomato. Bars $=0.5 \mathrm{~cm}$. 
On the subcellular level it is interesting that peroxisomes reacted with the strongest increase in glutathione content of all cell compartments at the early stages of the avirulent and virulent infection (12 and 24 hpi; Fig. 5 provides details). At the end of the infection period (48 hpi) both ascorbate and glutathione were strongly decreased compared with the control (Figs. 2 and 5) which correlated with a strong accumulation of $\mathrm{H}_{2} \mathrm{O}_{2}$ and $\mathrm{O}_{2}^{-}$ (Figs. 8 and 9) and the development of chlorotic and necrotic symptoms (Fig. 1). Similar results have also been obtained for peroxisomes during Botrytis cinerea infection in tomato where the initial increase of the antioxidative system in peroxisomes before the development of symptoms was followed by a strong decrease, which correlated with the appearance of infection symptoms $(23,24)$. The authors concluded that the initial increase of the antioxidative system was due to the necessity to detoxify $\mathrm{H}_{2} \mathrm{O}_{2}$, whereas the collapse of the antioxidative system in peroxisomes at the later stages promoted leaf senescence that favored diseases development. Recently, peroxisomes have also been described as subcellular indicators and sensors of plant stress since they are capable of releasing signaling molecules including ROS (for example $\mathrm{H}_{2} \mathrm{O}_{2}$ and $\mathrm{O}_{2}^{-}$) into the cytosol where they can trigger defense gene expression, which can lead to stress signaling and the activation of plant defense (9). As ROS are also key messenger molecules for signaling of pathogen-induced cell death, the observed collapse of the antioxidative system in peroxisomes (Figs. 2 and 5) and the correlating accumulation of ROS
(Figs. 8 and 9) at the later stages could be important triggers for the progress of diseases symptoms as observed during bacterial and fungal diseases $(9,23,24,38)$.

Ascorbate and glutathione contents in the cytosol and nuclei reacted similarly to the pathogen induced oxidative stress. An initial increase of ascorbate and glutathione contents (12 and 24 hpi) during the avirulent infection was followed by a drop of both antioxidants at the late stage of infection (48 hpi; Figs. 2 and 5 provide details), which correlated with ROS accumulation (Figs. 8 and 9) and symptom development (Fig. 1). Even though the exact roles of ascorbate and glutathione in nuclei during pathogen attack are not completely clear, their accumulation in the early stages of infection highlights the important role of these antioxidants in the protection of the nucleus. It has been recently addressed that antioxidants such as glutathione fulfill pivotal roles in nuclear function in plant and animal tissue since it is important for DNA synthesis, cell proliferation, and regulation of the nuclear matrix organization and proteins $(10,13)$. Additionally, it has been observed that the reduced form of glutathione in the nucleus protects DNA from oxidative damage, as the latter were negatively correlated with high reduced glutathione contents in the nucleus (15). Therefore, it could be possible that the strong elevation of ascorbate and glutathione observed in nuclei at the early stages of $P$. syringae infection (Figs. 2 and 5) could be important for maintaining and preserving function of nuclei during events of oxidative stress.

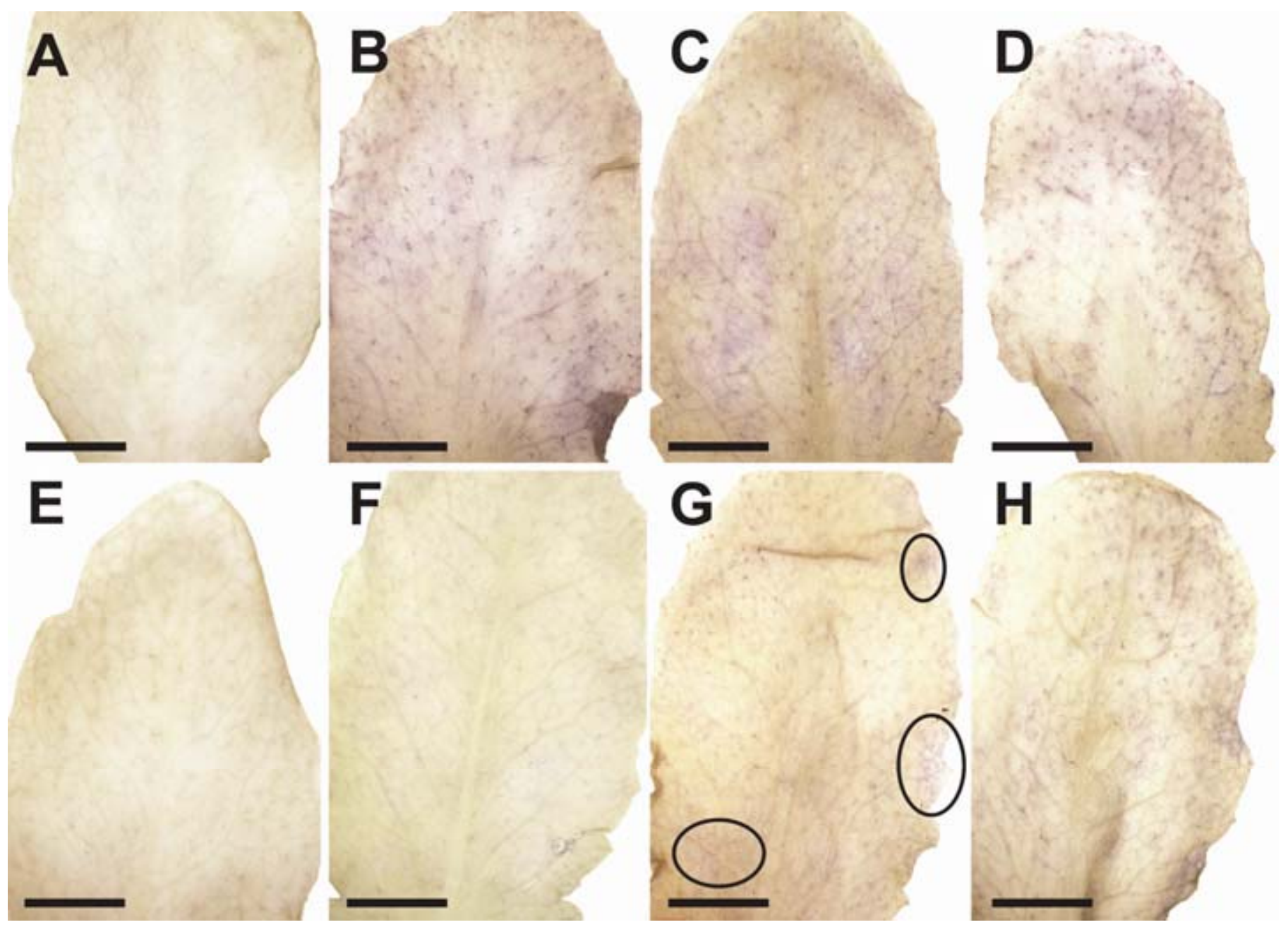

Fig. 9. Visualization of superoxide anions $\left(\mathrm{O}_{2}^{-}\right)$by nitroblue tetrazolium (NBT)-staining $12 \mathrm{~h}$ postinoculation (hpi) (B and F), 24 hpi (C and G), and 48 hpi (D and $\mathbf{H}$ ) with Pseudomonas syringae pv. tomato. No staining was observed on the controls at the time of inoculation (A) and $48 \mathrm{~h}$ after injection of a $10 \mathrm{mM}$ $\mathrm{MgCl}_{2}$ solution without bacteria (E). First $\mathrm{O}_{2}^{-}$staining in form of large stained areas was observed $12 \mathrm{hpi}(\mathbf{B})$ in the avirulent infection and remained similar at 24 and 48 hpi $(\mathbf{C}$ and $\mathbf{D})$. No staining could be observed 12 hpi on leaves inoculated with the virulent strain (F). First small spots of $\mathrm{O}_{2}{ }^{-}$accumulation (circles) were observed 24 hpi $(\mathbf{G})$, which increased in size $48 \mathrm{hpi}(\mathbf{H})$ on plants inoculated with the virulent strain of Pseudomonas syringae pv. tomato. Bars $=0.5 \mathrm{~cm}$. 
It is interesting that chloroplasts showed a strong accumulation of ascorbate over the whole investigation period in the virulent and avirulent infection (Fig. 2). Chloroplasts are considered to be the main production center for ROS during avirulent infections $(3,14,27,36)$. As ascorbate in A. thaliana is solely produced in mitochondria through the L-galactose pathway $(5,11,26,46)$, these results indicate that chloroplasts accumulate ascorbate through import from the cytosol despite a strong drop of ascorbate in most cell compartments starting at 24 hpi (Fig. 2). This observation is even more impressive considering that glutathione contents were significantly decreased 48 hpi in chloroplasts (Fig. 5), which indicates that at the later stages of infection ascorbate contents mainly take over the antioxidative protection of the chloroplasts.

A strong accumulation of ascorbate was observed over the whole period of investigation in vacuoles during the avirulent and virulent infection (Figs. 2 to 4 ). These results are interesting in context to the observed accumulation of ascorbate in vacuoles during other stress situations such as high light stress (49). It has been proposed recently that ascorbate is involved in the detoxification of $\mathrm{H}_{2} \mathrm{O}_{2}$, which diffuses into vacuoles during situations of oxidative stress (35), such as observed during $P$. syringae infection in this study. In vacuoles, ascorbate helps to reduce phenoxyl radicals, created by oxidation of phenols by $\mathrm{H}_{2} \mathrm{O}_{2}$, and is oxidized to mono- and dehydroascorbic acid, which is then transported into the cytosol for reduction to ascorbic acid (35). Therefore, the results of this study are another important indication of possible protective roles of ascorbate in vacuoles against oxidative stress.

Ascorbate and glutathione could not be detected in the apoplast of control and P. syringae-infected plants (Figs. 3A, 4A, 6A, and 7A). This is surprising as ascorbate in the apoplast is considered to be the only significant redox buffer $(12,31)$ and to play an important role in the protection against ozone $(4,8,33)$. Similar to ozone stress, $P$. syringae infection also causes the induction of ROS primary in the apoplast after entering the leaves through stomata and wounds and growing intercellularly in the infected tissue $(32,39)$. Thus, an accumulation of ascorbate (and glutathione) could have been expected also in the apoplast of $P$. syringae-infected plant tissue. The lack of labeling could either be explained by the inability of the present antibody approach to visualize ascorbate and glutathione in the apoplast or to the lack of an accumulation of antioxidants in the apoplast during $P$. syringae infection. In other plant species, antioxidants such as ascorbate and glutathione were found to occur in quite low amounts in the apoplast in comparison to foliar levels in nonstressed plants $(21,40,41,42,44)$ or could not be detected at all (25) even under situations of oxidative stress such as excessive light exposure (49). Additionally, a decrease in ascorbate and glutathione contents measured with biochemical methods in the apoplast has been observed in several plant species during pathogen attack $(40,41,42)$. Thus, the lack of labeling in the apoplast found in this study (Figs. 3A, 4A, 6A, and 7A) most likely indicates that ascorbate and glutathione in the apoplast play only a minor role during for the protection against ROS induced by $P$. syringae infection in A. thaliana plants.

Summing up, the study demonstrated that the occurrence of oxidative stress (12 and 24 hpi in the avirulent and virulent infection, respectively) correlated well with an accumulation of glutathione in most cell compartments, indicating the importance of glutathione in the protection against oxidative stress and basal plant resistance. A strong accumulation of ascorbate was additionally found prior to the occurrence of ROS (12 hpi) in the virulent infection indicating that ascorbate might take over additional roles in the defense response (e.g., signaling of basal resistance) besides solely the detoxification of ROS. Despite these differences, ascorbate and glutathione contents followed a general stress model in most cell compartments. An increase in ascorbate and glutathione contents at the early stages of infection emphasizes the importance of these antioxidants for stress signaling, protection and repair of plant compounds and metabolic pathways during the alarming and resistance phase. The strong drop of ascorbate and glutathione at the later stages of infection indicate the failure of protection and repair mechanisms, which correlated with ROS accumulation and symptom development such as the induction of chlorotic and necrotic lesions. On the subcellular level, peroxisomes could be defined as the hotspots of glutathione accumulation, which highlights the importance of peroxisomes in plant stress responses to pathogen attack.

\section{ACKNOWLEDGMENTS}

This work was supported by the Austrian Science Fund (FWF, P20619 and P22988 to B. Zechmann).

\section{LITERATURE CITED}

1. Abramovitch, R. B., and Martin, G. B. 2004. Strategies used by bacterial pathogens and suppress plant defense. Curr. Opin. Plant Biol. 7:356-364.

2. Alvarez, C., Bermudez, M. A., Romero, L. C., Gotor, C., and Garcia, I. 2011. Cysteine homeostasis plays an essential role in plant immunity. New Phytol. doi: 10.1111/j.1469-8137.2011.03889.x.

3. Asada, K. 2006. Production and scavenging of reactive oxygen species in chloroplasts and their functions. Plant Physiol. 141:391-396.

4. Baier, M., Kandlbinder, A., Golldack, D., and Dietz, K. J. 2005. Oxidative stress and ozone: Perception, signalling and response. Plant Cell Environ. 28:1012-1020.

5. Bartoli, C., Pastori, G., Kiddle, G., and Foyer, C. H. 2000. Ascorbate biosynthesis in mitochondria is linked to electron transport between complexes III and IV. Plant Physiol. 123:335-343.

6. Bender, C. L., Alarcón-Chaidez, F., and Gross, D. C. 1999. Pseudomonas syringae phytotoxins: Mode of action, regulation, and biosynthesis by peptide and polyketide synthetase. Microbiol. Mol. Biol. Rev. 63:266292.

7. Bertani, G. 1951. Studies on lysogenesis. I. The mode of phage liberation by lysogenic Escherichia coli. J. Bact. 62:293-300.

8. Conklin, P. L., and Barth, C. 2004. Ascorbic acid, a familiar small molecule intertwined in the response of plants to ozone, pathogens, and the onset of senescence. Plant Cell Environ. 27:959-970.

9. del Rio, L. A. 2011. Peroxisomes as a cellular source of reactive nitrogen species signal molecules. Arch. Biochem. Biophys. 506:1-11.

10. Diaz-Vivancos, P., Wolff, T., Markovic, J., Pallardo, F. V., and Foyer, C. H. 2010. A nuclear glutathione cycle within the cell cycle. Biochem. J. 431:169-178.

11. Dowdle, J., Ishikawa, T., Gatzek, S., Rolinski, S., and Smirnoff, N. 2007. Two genes in Arabidopsis thaliana encoding GDP-L-galactose phosphorylase are required for ascorbate biosynthesis and seedling viability. Plant J. 52:673-689.

12. Foyer, C. H., and Noctor, G. 2009. Redox regulation and photosynthetic organisms: Signaling, acclimation, and practical implications. Antiox. Redox. Signal. 11:861-905.

13. Go, Y. M., and Jones, D. P. 2010. Redox control system in the nucleus: Mechanisms and functions. Antiox. Redox. Signal. 12:489-509.

14. Goodman, R. N., and Novacky, A. J. 1994. The Hypersensitive Reaction in Plants to Pathogens. American Phytopathological Society, St. Paul, $\mathrm{MN}$.

15. Green, R. M., Graham, M., O’Donovan, M. R., Chipman, J. K., and Hodges, N. J. 2006. Subcellular compartmentalization of glutathione: Correlations with parameters of oxidative stress related to genotoxicity. Mutagenesis 21:383-390.

16. Großkinsky, D. K., Naseem, M., Abdelmohsen, U. R., Plickert, N., Engelke, T., Griebel, T., Zeier, J., Novák, O., Strnad, M., Pfeifhofer, H., van der Graaff, E., Simon, U., and Roitsch, T. 2011. Cytokinins mediate resistance against Pseudomonas syringae in tobacco through increased antimicrobial phytoalexin synthesis independent of salicylic acid signaling. Plant Physiol. 157:815-830.

17. Heiser, I., Oßwald, W., and Elstner, E. F. 1998. The formation of reactive oxygen species by fungal and bacterial phytotoxins. Plant Physiol. Biochem. 36:703-713.

18. Höller, K., Király, L., Künstler, A., Müller, M., Gullner, G., Fattinger, M., and Zechmann, B. 2010. Enhanced glutathione metabolism is correlated with sulfur induced resistance in Tobacco mosaic virus-infected genetically susceptible Nicotiana tabacum plants. Mol. Plant-Microbe Interact. 23:1448-1459.

19. Jabs, T., Dietrich, R. A., and Dangl, J. L. 1996. Initiation of runaway cell death in an Arabidopsis mutant by extracellular superoxide. Science 273:1853-1856. 
20. Katagiri, F., Thilmony, R., and He, S. Y. 2002. The Arabidopsis thalianaPseudomonas syringae interaction. The Arabidopsis book. DOI: 10.1199/tab.0039.

21. Kollist, H., Moldau, H., Oksanen, E., and Vapaavuori, E. 2001. Ascorbate transport from the apoplast to the symplast in intact leaves. Physiol. Plant 113:377-383.

22. Kranner, I., Minibayeva, F. V., Beckett, R. P., and Seal, C. E. 2010. What is stress? Concepts, definitions and applications in seed science. New Phytol. 188:655-673.

23. Kuźniak, E., and Sklodowska, A. 2005. Compartment-specific role of the ascorbate-glutathione cycle in the response of tomato leaf cells to Botrytis cinerea infection. J. Exp. Bot. 56:921-933.

24. Kuźniak, E., and Sklodowska, A. 2005. Fungal pathogen-induced changes in the antioxidant systems of leaf peroxisomes from infected tomato plants. Planta 222:192-200.

25. Liso, R., de Tullio, M. C., Ciraci, S., Balestrini, R., La Rocca, N., Bruno, L., Chiappetta, A., Bitoni, M. B., Bonfante, P., and Arrigoni, O. 2004. Localization of ascorbic acid, ascorbic acid oxidase, and glutathione in roots of Cucurbita maxima L. J. Exp. Bot. 55:2589-2597.

26. Millar, A. H., Mittova, V., Kiddle, G., Heazlewood, J. L., Bartoli, C. G., Theodoulou, F. L., and Foyer, C. H. 2003. Control of ascorbate synthesis by respiration and its implications for stress responses. Plant Physiol. 133:443-447.

27. Montillet, J. L., Chamnongpol, S., Rusterucci, C., Dat, J., van de Cotte, B., Agnel, J. P., Battesti, C., Inze, D., Van Breusegem, F., and Triantaphylides, C. 2005. Fatty acid hydroperoxides and $\mathrm{H}_{2} \mathrm{O}_{2}$ in the execution of hypersensitive cell death in tobacco leaves. Plant Physiol. 138:1516-1526.

28. Noctor, G. 2006. Metabolic signalling in defence and stress: The central roles of soluble redox couples. Plant Cell Environ. 29:409-425.

29. Noctor, G., Queval, G., Mhamdi, A., Chaouch, S., and Foyer, C. H. 2011. Glutathione. The Arabidopsis Book 9, e0142. doi:10.1199/tab.0142.

30. Nomura, K., Melotto, M., and He, S. Y. 2005. Suppression of host defense in compatible plant-Pseudomonas syringae interactions. Curr. Opin. Plant Biol. 8:361-368.

31. Pignocchi, C., and Foyer, C. H. 2003. Apoplastic ascorbate metabolism and its role in the regulation of cell signalling. Curr. Opin. Plant Biol. 6:379-389.

32. Rico, A., McCraw, S. L., and Preston, G. M. 2011. The metabolic interface between Pseudomonas syringae and plant cells. Curr. Opin. Microbiol. 14:31-38.

33. Sandermann, H. 2008. Ecotoxicology of ozone: Bioactivation of extracellular ascorbate. Biochem. Biophys. Res. Commun. 366:271-274.

34. Sørensen, S. 1909. Über die Messung und die Bedeutung der Wasserstoffionenkonzentration bei Enzymatischen prozessen (mit einer ergänzung). Biochem. Zeit. 21:131-304.

35. Takahama, U. 2004. Oxidation of vacuolar and apoplastic phenolic substrates by peroxidase: Physiological significance of the oxidation reactions. Phytochem. Rev. 3:207-219.

36. Tang, X., Xie, M., Kim, Y. J., Zhou, J., Klessig, D. F., and Martin, G. B. 1999. Overexpression of Pto activates defense responses and confers broad resistance. Plant Cell 11:15-30.

37. Tausz, M. 2001. The role of glutathione in plant response and adaptation to natural stress. Pages 101-122 in: Significance of Glutathione to Plant Adaptation to the Environment. D. Grill, M. Tausz, and L. J. De Kok, eds. Kluwer Academic Publishers, Dordrecht, Boston, London.

38. Torres, M. A. 2010. ROS in biotic interactions. Physiol. Plant 138:414429.

39. Torres, M. A., Jones J. D. G., and Dangl, J. L. 2006. Reactive oxygen species signaling in response to pathogens. Plant Physiol. 141:373-378.

40. Vanacker, H., Carver, T. L. W., and Foyer, C. H. 1998. Pathogen-induced changes in the antioxidant status of the apoplast in barley leaves. Plant Physiol. 117:1103-1114.

41. Vanacker, H., Foyer, C. H., and Carver, T. L. W. 1998. Changes in apoplastic antioxidants induced by powdery mildew attack in oat genotypes with race non-specific resistance. Planta 208:444-452.

42. Vanacker, H., Harbinson, J., Ruisch, J., Carver, T. L. W., and Foyer, C. H. 1998. Antioxidant defences of the apoplast. Protoplasma 205:129-140.

43. Van Breusegem, F., and Dat, J. F. 2006. Reactive oxygen species in plant cell death. Plant Physiol. 141:384-390.

44. Van Hove, L. W. A., Bossen, M. E., San Gabino, B. G., and Sgreva, C. 2001. The ability of apoplastic ascorbate to protect poplar leaves against ambient ozone concentrations: A quantitative approach. Environ. Poll. 114:371-382.

45. Weigel, D., and Glazebrook, J. 2002. Diaminobenzidine Stain for Hydrogen Peroxide. In: Arabidopsis-A Laboratory Manual. Cold Spring Harbor Laboratory, Cold Spring Harbor, NY.

46. Wheeler, G. L., Jones, M. A., and Smirnoff, N. 1998. The biosynthetic pathway of vitamin C in higher plants. Nature 393:365-369.

47. Zechmann, B., Mauch, F., Sticher, L., and Müller, M. 2008. Subcellular immunocytochemical analysis detects the highest concentrations of glutathione in mitochondria and not in plastids. J. Exp. Bot. 59:40174027.

48. Zechmann, B., Müller, M., and Zellnig, G. 2006. Intracellular adaptations of glutathione content in Cucurbita pepo (L.) induced by reduced glutathione and buthionine sulfoximine treatment. Protoplasma 227:197209.

49. Zechmann, B., Stumpe, M., and Mauch, F. 2011. Immunocytochemical determination of the subcellular distribution of ascorbate in plants. Planta 233:1-12.

50. Zechmann, B., Zellnig, G., and Müller, M. 2005. Changes in the subcellular distribution of glutathione during virus infection in Cucurbita pepo (L.). Plant Biol. 7:49-57.

51. Zechmann, B., Zellnig, G., Urbanek-Krajnc, A., and Müller, M. 2007. Artificial elevation of glutathione affects symptom development in ZYMV-infected Cucurbita pepo L. plants. Arch. Virol. 152:747-762. 